\title{
The Effects of Cumulative Risks and Promotive Factors on Urban Adolescent Alcohol and Other Drug Use: A Longitudinal Study of Resiliency
}

\author{
Krzysztof Ostaszewski • Marc A. Zimmerman
}

Published online: 27 September 2006

(C) Springer Science+Business Media, LLC 2006

\begin{abstract}
Resiliency theory provides a conceptual framework for studying why some youth exposed to risk factors do not develop the negative behaviors they predict. The purpose of this study was to test compensatory and protective models of resiliency in a longitudinal sample of urban adolescents (80\% African American). The data were from Years 1 (9th grade) and 4 (12th grade). The study examined effects of cumulative risk and promotive factors on adolescent polydrug use including alcohol, tobacco and marijuana. Cumulative measures of risk/promotive factors represented individual characteristics, peer influence, and parental/familial influences. After controlling for demographics, results of multiple regression of polydrug use support the compensatory model of resiliency both cross-sectionally and longitudinally. Promotive factors were also found to have compensatory effects on change in adolescent polydrug use. The protective model of resiliency evidenced cross-sectionally was not supported in longitudinal analysis. The findings support resiliency theory and the use of cumulative risk/promotive measures in resiliency research. Implications focused on utilizing multiple assets and resources in prevention programming are discussed.
\end{abstract}

Keywords Adolescents · Protective factors - Risk factors · Alcohol $\cdot$ Tobacco $\cdot$ Marijuana use

K. Ostaszewski

Institute of Psychiatry and Neurology,

Warsaw, Poland

M. A. Zimmerman

HBHE, School of Public Health, University of Michigan,

Ann Arbor, MI 48109-2029, USA

\section{Introduction}

Despite the traditional focus on risks (e.g., Blitstein, Murray, Lytle, Birnbaum, \& Perry, 2005), researchers are becoming increasingly aware of the importance of positive factors in youths' lives, and their effect on adolescent alcohol and other drug use (Bryant \& Zimmerman, 2002; Fergus \& Zimmerman, 2005; Griffin, Botvin, Scheier, Doyle, \& Williams, 2003; Hawkins, Catalano, \& Miller, 1992; Jessor, Van Den Bos, Vanderryn, Costa, \& Turbin, 1995; Resnick et al., 1997; Wills, Vaccaro, \& McNamara, 1992; Zimmerman, Salem, \& Notaro, 2000). Positive factors are vital because they contribute to our understanding of developmental processes and provide clues for designing prevention strategies. This shift towards positive factors is evidenced by the burgeoning research on resiliency theory (Fraser, Richman, \& Galinsky, 1999; Kegler et al., 2005; Kumpfer, 1999; Luthar, Cicchetti, \& Becker, 2000; Zimmerman \& Arunkumar, 1994), social ecological approaches in prevention research (Bronfenbrenner, 1986; Kumpfer \& Turner, 1990/91), and positive youth development movement (Catalano, Berglund, Ryan, Lonczak, \& Hawkins, 2002; National Research Council and Institute of Medicine, 2002). Adolescent resiliency is also linked to empowerment theory through its focus on strengths (versus problems), the role of social linkages and participation, and the ecological nature of person-environment interaction (Zimmerman, 2000, 2005). Zimmerman (2005) points out that the developmental context of empowerment theory is connected to adolescent resilience through common issues of control and confidence, taking action to overcome risk, and intergenerational connections for support, guidance, and mentoring.

In a review of the research literature on resiliency research and adolescent health, Fergus and Zimmerman (2005) describe the notion of promotive factors (this term was coined 
first by Sandler, Wolchik, Davis, Haine, \& Ayers, 2003). Promotive factors include individual assets and contextual resources that operate to enhance healthy development. They are a counterpart to risk factors and play a role in helping youth overcome the negative effects risks pose on development. These promotive factors are vital for resiliency theory because they help compensate for or protect against the effects of risks on healthy development. Fergus and Zimmerman (2005) describe compensatory, protective, and inoculation models in which promotive factors may operate. In their review of research on resiliency, Fergus and Zimmerman suggest that the term protective factors refers to interaction effects to help clarify and distinguish different ways promotive factors may reduce the negative consequences of risk factors. They suggest that the more general term promotive factors is preferable because it encompasses the many different ways positive factors in youths' lives may be associated with risks to reduce their effects on negative outcomes. Resiliency theory emphasizes the role of promotive factors among children growing up in adverse environments, and provides a framework for understanding why some children and adolescents who are exposed to high risk do not develop negative health and social outcomes (Garmezy, 1985; Luthar \& Zigler, 1991; Rutter, 1987). Two models of resiliency include: the compensatory model (direct effect) and risk-protective model (interaction effect) (Garmezy, Masten, \& Tellegen, 1984; Jessor et al., 1995; Zimmerman \& Arunkumar, 1994).

The compensatory model implies that promotive factors (e.g., parental support, pro-social activities, church attendance) can counteract the effects of risk factors. In other words, promotive factors may compensate for exposure to risk factors. The risk-protective model assumes that promotive factors buffer or moderate the negative influence of exposure to risk. Within this model, promotive factors interact with risks and lessen or modify their negative effect on adolescent behavior. Several studies provide empirical evidence supporting these kinds of associations between promotive factors and adolescent health behavior. Zimmerman et al. (2002), for example, in a sample of 770 urban, predominantly African American 12th graders found that having a natural mentor has a compensatory, but not a protective effect on adolescent problem behaviors including substance use, and delinquent and violent behavior. The same study, however, indicated both compensatory and protective effects of natural mentors on adolescents' positive school attitudes. Several studies have been done to explore the compensatory or protective effects of single factors measured in different settings: family, school, peers, community and individual level. A study conducted in a sample of 568 urban adolescents (10th and 11th grade) supported the notion that fathers' involvement (i.e., time spent, school and social support) has a compensatory effect on adolescent problem behavior
(Zimmerman et al., 2000). Resnick et al. (1997) found in the National Longitudinal Study of Adolescent Health that parental and school connectedness along with religious identity (involvement and importance) have a compensatory effect on use of three gateway substances (cigarettes, alcohol and marijuana) and other risk behaviors. The moderating effect of these factors, however, was not found in this study. Results of another multiethnic adolescent study, with a sample of 1289 urban 11-13 year-olds indicated that several protective factors including parent support, academic competence and positive affect were directly and also indirectly related to lower level of adolescent substance use (Wills et al., 1992). They found that the effect of having negative life events (risk factor) on adolescent substance use was reduced by adequate social support from parents.

In general, empirical evidence supports the notion that promotive factors can have compensatory or protecting effects on risk factors associated with drug use and other adolescent problem behaviors (Jessor et al., 1995; Newcomb \& Felix-Ortiz, 1992; Wills et al., 1992; Simons-Morton, Hartos, \& Haynie, 2004; Zimmerman et al., 2000). Parent-child relationship and support (Resnick et al., 1997; Salem, Zimmerman, \& Notaro, 1998; Wills \& Cleary, 1996) school connectedness (Resnick et al., 1997), individual competences (Griffin et al., 2003; Scheier, Botvin, \& Baker, 1997), intolerance of deviance and commitment toward school education (Jessor et al., 1995), religiosity (Wills, Yaeger, \& Sandy, 2003) have all been found to help youth be resilient against the effects of risks.

Most of the research on adolescent resiliency, however, has focused on single risk and promotive factors. This approach does not consider the cumulative effects of these factors. Individual promotive factors may not be sufficient to achieve compensatory or protective effect in the face of a particular constellation of risks or within specific social contexts (Rutter, 1987). It becomes increasingly clear that the process of resiliency involves a complex interaction between an individual's constellation of risks, assets and resources. In order to overcome this limitation, some researchers have examined the compensatory and protective effect of promotive factors by developing cumulative measures of risks and promotive factors (Bowen \& Flora, 2002; Dekovic, 1999; DeWit, Silverman, Goodstadt, \& Stoduto, 1995; Epstein, Botvin, Griffin, \& Diaz, 2001; Jessor et al., 1995; Newcomb \& Felix-Ortiz, 1992; Pollard, Hawkins, \& Arthur, 1999). This methodology is supported both theoretically by the social ecological approach to human development (Bronfenbrenner, 1986, Kumpfer \& Turner, 1990/91), and empirically by a number of studies demonstrating variety of risk and protective factors influencing problem behaviors (e.g., Hawkins et al., 1992). Social ecological theory looks at a child's development within the system of the interactions between a child, immediate environment (family, school, and peers) 
and larger social environment (community, society, culture), as well as interactions among different levels of the environment (Bronfenbrenner, 1986; Kumpfer \& Turner, 1990/91). In other words, this notion of common cross-context processes in human development provides a rationale for the use of multiple risk and promotive factor approach in resiliency research rather than single factor approach.

Risk and promotive factors empirically identified in adolescent problem behaviors are usually categorized in four broad domains, most often including individual characteristics (e.g., self-acceptance, coping skills, academic performance), peer influences (e.g., peer health-related behaviors, friends' support, friends' positive activities), family relationships (e.g., parent-child relationship, family support, family conflicts), and community characteristics (e.g., drug availability in the community, high availability of after-school activities). Cumulative measures of risk and protection usually contain several variables that have been identified within these domains. The number of factors used to create these measures varies across studies, from a relatively low number of factors-(e.g., six risk and six promotive factors) in the Dekovic study (1999), to over 20 indicators of risk and promotive factors in another study (Bowen \& Flora, 2002).

Newcomb and Felix-Ortiz (1992) in their pioneering study utilizing cumulative measures of risk and promotive factors demonstrated both a compensatory and protective effect in adolescent and young adult substance use. Similar studies support the compensatory model for substance use (DeWit et al., 1995; Pollard et al., 1999); and more generally, for different problem behaviors (Dekovic, 1999; Jessor et al., 1995), but the protective model of resiliency was not supported in either of these studies. Few studies of cumulative risk and promotive factors have used longitudinal data (Jessor et al., 1995 is a notable exception), and fewer have focused on nonwhite samples. Our study attempts to address these issues by testing compensatory and protective models of resiliency longitudinally in a sample of predominantly African American adolescents.

\section{Poly drug use}

From a developmental perspective, experimentation with alcohol, cigarettes, and to a lesser extent, marijuana, is considered by some to be a normal part of adolescent exploration and transition to adulthood (Baer, MacLean, \& Marlatt, 1998; Clark \& Winters, 2002). The broad spectrum of consequences related to adolescent substance use includes neglecting responsibilities, interpersonal problems with friends, family members and teachers, poor performance at school or work, drunk driving, physical and psychological impairment (Baer et al., 1998; O’Malley, Johnston, \& Bachman, 1998). In addition, substance use by adolescents is associated with unprotected or coercive sexual activity, suicidal behavior and victimization (Windle, 1994; Windle, Miller-Tutzauer, \& Domenico, 1992).

Although the study of individual substances provides useful information, the development of polydrug use index to measure substance use behavior among adolescents is also beneficial. Cigarettes, alcohol and marijuana are consistently the most prevalent drugs among youth (Johnston, O'Malley, \& Bachman, 2003; O'Malley et al., 1998). Moreover, the use of these substances is highly correlated during adolescence. In a study utilizing a latent growth curve methodology, Duncan, Duncan, Biglan, and Ary (1998) found a common trajectory across developmental period with significant increases in all these three substances. Correlations among the slopes for alcohol, cigarette, and marijuana use ranged from 0.54 to 0.70 . The idea of creating a polydrug use index for adolescents is also supported by the gateway theory (Kandel, Yamaguchi, \& Chen, 1992). According to this theory, alcohol, cigarettes and marijuana might have a similar function in the progress to more dangerous illegal drugs. In other words, they are all gateway drugs that might lead to other illegal drug use. Newcomb and Felix-Ortiz (1992) also noted that "polydrug use is a robust, reliable, and meaningful construct of drug use behavior during late adolescence and young adulthood" (p. 292).

\section{Method}

Sample

The sample includes 850 ninth-grade adolescents who participated in a longitudinal study. They were selected from the four main public high schools in a small city in Michigan. Two schools were predominantly African American (over $90 \%$ ), and two schools included approximately $60 \%$ African American students. Students were sampled if they met the following criteria: (1) having an initial GPA of 3.0 or lower, and (2) not being diagnosed by the school as emotionally impaired or developmentally disabled. The grade cutoff was used because one goal of the larger project was to study youths at risk for leaving school before graduation. About half $(49 \%)$ of the total ninth-grade population was selected. The original sample was evenly split by gender $(50 \%$ female), and included $80 \%$ African American students, $17 \%$ White students, and 3\% mixed African American and White students. Their average age was $14.6(S D=0.66)$.

The data reported in this study were from Years 1 (9th grade) and 4 (12th grade). The 12th-grade sample included 770 adolescents which constituted a $91 \%$ response rate from Year 1 to Year 4. Due to missing data on any study variable, Year 1 included complete data for 624 youth $(73 \%$ of original sample), and Year 4 included complete data for 531 youth $(63 \%)$. 


\section{Procedure}

Structured, face-to-face interviews were conducted with students in school during schools hours by African American and White male and female trained interviewers. Students who could not be found in school were interviewed in a community setting (e.g., home, Urban League office). When the 50-60 min interview was done, participants completed a selfadministrated pencil-and-paper questionnaire about drug and alcohol use. Participants were informed that all information was confidential and protected.

\section{Measures}

\section{Polydrug use}

Polydrug use was measured by combining a measure of cigarette use, alcohol use and marijuana use. Frequency of use was assessed on 7-point Likert scale. Cigarette use was measured by last month use only $(1=$ not at all, $7=2$ packs or more per day) based on the notion that cigarettes are most often used on a regular basis because they are readily available and easily obtained by youth. Alcohol and marijuana use were measured by last year use and last month use $(1=0$ times, $7=40$ or more times). The correlations between last month and last year use of these substances were 0.79 for alcohol to 0.88 for marijuana. These cigarette, alcohol and marijuana use items were the same as those used in the Monitoring the Future study (Johnston et al., 2003). A polydrug use index was formed by summing z-scores from these five self-report items. We included last year use for alcohol and marijuana to increase variance in the measure, but we did not assess last year use for cigarettes.

The mean for polydrug use index in Year 1 was -0.07 $(S D=4.01, \min -2.70, \max 19.64$, skewness $=1.99)$ and in Year 4 was $0.02(S D=3.98$, $\min -3.41$, max 14.97 , skewness $=1.19$ ). For 30-day use, our sample showed a $25 \%$ (Year 1)/34\% (Year 4) prevalence of cigarette smoking, 28\% (Year 1)/34\% (Year 4) of alcohol drinking, and 25\% (Year $1) / 34 \%$ (Year 4 ) of marijuana use.

\section{Promotive and risk factor measures}

Seventeen variables were selected for study as promotive factors and fifteen variables as risk factors. Variables were assigned as either protective factors or risk factors based on a large body of previous research assessing factors related to adolescent substance use (Arthur, Hawkins, Pollard, Catalano, \& Baglioni, 2002; Hawkins et al., 1992, Kumpfer, Olds, Alexander, Zucker, \& Gary, 1998), and sound theories of adolescent substance use (Petraitis, Flay, \& Miller, 1995). Both promotive and risk factors were selected from three broad domains, representing: (1) individual character- istic, (2) peer influences, and (3) parental/familial influences. These three domains of factors reflect two levels described in social ecological theory (Bronfenbrenner, 1986): an individual and immediate environment (family, school and peers) level of influence. These factors were chosen as likely correlates or predictors of substance use and were measured in Year 1. Table 1 presents the independent variables along with the number of items in each measure, means and standard deviations, Cronbach's alphas if appropriate, and a sample item from each measure.

Individual-level factors included sixteen variables (eight promotive and eight risks): school positive attitudes (Hawkins et al., 1992), school relevance, orientation to the future, self-acceptance (Stein, Newcomb, \& Bentler, 1986), active coping (John Henryism—James, Strogatz, Wing, \& Ramsey, 1987), church attendance, church activities, religious coping, and approval of violence, observed violence, being a victim of violence, violent behavior, early substance use, held back a grade in school, skipped whole days of school, and skipped classes. Peer influences were measured by seven variables (three promotive and four risks): friends' support (Procidano \& Heller 1983), friends' positive activities and school influences, closeness with peers (Stein et al., 1986), friends who use alcohol (Stacy, Newcomb, \& Bentler, 1992), friends who use drugs (Dielman, Butchart, \& Shope, 1991), friends' aggressive or delinquent behavior, and friends who cut/suspended/dropped out of school. Family-level factors included nine variables (six promotive and three risks): involvement in making family decisions (Moos \& Moos, 1981), closeness with family (Newcomb, Maddahian, \& Bentler, 1986), parental support (Procidano \& Heller, 1983), time shared with mother, time shared with father, family participation in recreational or fun events (Moos \& Moos, 1981), all drug and alcohol use by adults raising the respondent, fighting and acting out in family (Moos \& Moos, 1981) and knife or gun carried by adults raising the respondent.

The upper $25 \%$ of the distribution of each of the variables was designated as either a promotive factor or risk factor, depending on the variable. The actual cutoff points were assigned as close to the upper $25 \%$ threshold as each variable distribution would allow. Parental support, for example, ranged from 1 to 5 (cutoff point was 4.6). The actual percentage of students with parental support score equal to or greater than 4.6 was $27 \%$. When the distribution of a variable showed little variance around the $25 \%$ level, some a priori criteria were used to find natural cutoff points. Thus, among all independent variables, the actual percentage of sample above the cutoff ranged from $17 \%$ (knife or gun carried by adults raising a student) to $46 \%$ (self-acceptance). Similar procedures for developing cumulative indices were used by other researchers (Bowen \& Flora, 2002; DeWit et al., 1995; Newcomb \& Felix-Ortiz, 1992). 
Table 1 Descriptive statistics and individual measures for cumulative risk and promotive factors

\begin{tabular}{|c|c|c|c|c|}
\hline Risk Factors (number of items) & $\overline{\mathrm{x}}$ & SD & $\alpha$ & Sample item (type of scale used) \\
\hline \multicolumn{5}{|l|}{ Individual/behavioral } \\
\hline Approval of violence to solve problems (3) & 1.63 & 0.69 & 0.62 & $\begin{array}{l}\text { Fighting is the best way to solve problems (4-pt Likert, } 1= \\
\text { strongly disagree, } 4=\text { strongly agree) }\end{array}$ \\
\hline Observed violence (2) & 2.22 & 1.18 & $r=0.52^{a}$ & $\begin{array}{l}\text { See someone get shot, stabbed, or beaten up (5-pt Likert, } \\
1=0 \text { times, } 5=4+\text { times })\end{array}$ \\
\hline Being victim of violence (3) & 1.47 & 0.63 & 0.54 & $\begin{array}{l}\text { Had someone physically assault or hurt you (5-pt Likert, } \\
1=0 \text { times, } 5=4+\text { times) }\end{array}$ \\
\hline Violent behavior by student (7) & 1.34 & 0.52 & 0.73 & $\begin{array}{l}\text { How often have you gotten into a fight in school or at work } \\
\text { (5-pt Likert, } 1=0 \text { times, } 5=4+\text { times })\end{array}$ \\
\hline Early substance use (3) & 12.23 & 1.55 & 0.55 & How old were you when you first time smoked a cigarette \\
\hline Held back (1) & 1.63 & 0.48 & NA & $\begin{array}{l}\text { Have you ever held back (made to repeat) a grade in school } \\
(\text { yes }=1, \text { no }=2)\end{array}$ \\
\hline Skipped whole days (1) & 1.68 & 1.39 & NA & $\begin{array}{l}\text { How many whole days of school have you skipped or cut } \\
(7 \mathrm{pt} \text { Likert, } 1=0,7=11+)\end{array}$ \\
\hline Skipped classes (1) & 1.75 & 1.13 & NA & $\begin{array}{l}\text { During the last four weeks how often have gone to school, } \\
\text { but skipped a class ( } 6 \text {-pt Likert, } 1=\text { not at all, } 6=\text { more } \\
\text { than } 20 \text { times) }\end{array}$ \\
\hline \multicolumn{5}{|l|}{ Promotive factors (number of items) } \\
\hline School positive attitudes (7) & 2.79 & 0.64 & 0.71 & $\begin{array}{l}\text { I like school }(5 \text {-pt Likert, } 1=\text { strongly disagree, } \\
5=\text { strongly agree })\end{array}$ \\
\hline School relevance (3) & 3.61 & 0.80 & 0.52 & $\begin{array}{l}\text { Last year, how interesting were most of your classes for } \\
\text { you (5-pt Likert, } 1=\text { very dull, } 5=\text { very interesting) }\end{array}$ \\
\hline Orientation towards the future (2) & 4.42 & 0.78 & $r=0.43^{a}$ & $\begin{array}{l}\text { How likely is it that you will graduate from high school } \\
\text { (5-pt Likert, } 1=\text { not at all likely to, } 5=\text { very likely) }\end{array}$ \\
\hline Self-acceptance (4) & 4.46 & 0.73 & 0.66 & $\begin{array}{l}\text { Unhappy with myself / Happy with myself ( } 5 \text {-pt Likert, } \\
1=\text { first statement is true for me, } 5=\text { second statement is } \\
\text { true for me) }\end{array}$ \\
\hline John Henryism (8) & 4.12 & 0.58 & 0.70 & $\begin{array}{l}\text { Hard work is the best possible way for someone to get } \\
\text { ahead in life (5-pt Likert, } 1=\text { not true, } 5=\text { very true) }\end{array}$ \\
\hline Church attendance (1) & 4.40 & 2.12 & NA & $\begin{array}{l}\text { How often do you attend religious services (7-pt Likert, } \\
1=\text { not at all, } 7=\text { more than once a week) }\end{array}$ \\
\hline Church activities (1) & 1.55 & 0.50 & NA & Do you participate in any church activities $($ yes $=1$, no $=2$ ) \\
\hline Religious coping (1) & 3.59 & 1.28 & NA & $\begin{array}{l}\text { My religious faith helps me to cope during times of } \\
\text { difficulty (5-pt Likert, } 1=\text { not true, } 5=\text { very true) }\end{array}$ \\
\hline \multicolumn{5}{|r|}{ (1) } \\
\hline Friends who use alcohol (4) & 1.84 & 0.84 & 0.77 & $\begin{array}{l}\text { How many of your friends drink beer or wine at least once a } \\
\text { month }(5 \text {-pt Likert, } 1=\text { none, } 5=\text { all })\end{array}$ \\
\hline Friends who use drugs (10) & 1.32 & 0.39 & 0.74 & $\begin{array}{l}\text { How many of your friends smoke marijuana at least once a } \\
\text { month }(5 \text {-pt Likert, } 1=\text { none, } 5=\text { all })\end{array}$ \\
\hline Friends aggressive or delinquent behavior (5) & 1.87 & 0.75 & 0.75 & $\begin{array}{l}\text { How many of your friends have carried a knife or razor } \\
(5 \text {-pt Likert, } 1=\text { none, } 5=\text { all })\end{array}$ \\
\hline Friends who cut/suspended/ dropped out of school (3) & 3.03 & 0.99 & 0.65 & $\begin{array}{l}\text { How many of your friends have been suspended from } \\
\text { school }(5 \text {-pt Likert, } 1=\text { none, } 5=\text { all })\end{array}$ \\
\hline \multicolumn{5}{|l|}{ Promotive factors (number of items) } \\
\hline Friends support (5) & 3.14 & 0.95 & 0.82 & $\begin{array}{l}\text { I rely on my friends for emotional support (5-pt Likert, } 1= \\
\text { not true, } 5=\text { very true) }\end{array}$ \\
\hline Friends positive activities \& school influences (5) & 2.60 & 0.71 & 0.64 & $\begin{array}{l}\text { How many of your friends go to church regularly }(5-\mathrm{pt} \\
\text { Likert, } 1=\text { none, } 5=\text { all })\end{array}$ \\
\hline Closeness \& relations with peers (4) & 4.04 & 0.84 & 0.54 & $\begin{array}{l}\text { Not very happy with my friends/ Pretty satisfied with my } \\
\text { friends }(5 \text {-pt Likert, } 1=\text { first statement is true for me, } \\
5=\text { second statement is true for me) }\end{array}$ \\
\hline \multicolumn{5}{|l|}{ Parental/familial } \\
\hline All drug and alcohol use by adults raising student (13) & 1.14 & 0.24 & 0.74 & $\begin{array}{l}\text { Does the most important person in raising you get drunk } \\
\text { (5-pt Likert, } 1=\text { never, } 5=\text { very often) }\end{array}$ \\
\hline Fighting and acting out in family (5) & 1.81 & 0.44 & 0.76 & $\begin{array}{l}\text { We fight in our family (4-pt Likert, } 1=\text { hardly ever, } \\
4=\text { often) }\end{array}$ \\
\hline
\end{tabular}


Table 1 Continued

\begin{tabular}{|c|c|c|c|c|}
\hline Risk Factors (number of items) & $\overline{\mathrm{x}}$ & SD & $\alpha$ & Sample item (type of scale used) \\
\hline Knife or guns carried by adults raising student (2) & 1.20 & 0.54 & $r=0.61^{a}$ & $\begin{array}{l}\text { Does the most important person in raising you carry a gun } \\
(5 \text {-pt Likert, } 1=\text { never, } 5=\text { very often) }\end{array}$ \\
\hline \multicolumn{5}{|l|}{ Promotive factors (number of items) } \\
\hline Student's involvement in making family decisions (3) & 2.29 & 0.81 & 0.65 & $\begin{array}{l}\text { Family members make the rules together ( } 4 \text {-pt Likert, } 1= \\
\text { hardly ever, } 4=\text { often) }\end{array}$ \\
\hline Closeness with family (4) & 3.68 & 0.95 & 0.56 & $\begin{array}{l}\text { Family is not very close at all/Family is very close to each } \\
\text { other }(5 \text {-pt Likert, } 1=\text { first statement is true for me, } \\
5=\text { second statement is true for me })\end{array}$ \\
\hline Parental support (6) & 3.90 & 1.02 & 0.87 & $\begin{array}{l}\text { My parents are good at helping me solve problems ( } 5 \text {-pt } \\
\text { Likert, } 1=\text { not true, } 5=\text { very true) }\end{array}$ \\
\hline Time shared with mother (1) & 3.70 & 1.56 & NA & $\begin{array}{l}\text { In an average week, how much time do you spend with } \\
\text { your mother in shared activities (6-pt Likert, } 1=\text { none, } \\
6=\text { a lot of time) }\end{array}$ \\
\hline Time shared with father (1) & 2.56 & 1.59 & NA & $\begin{array}{l}\text { In an average week, how much time do you spend with } \\
\text { your father in shared activities (6-pt Likert, } 1=\text { none, } \\
6=\text { a lot of time) }\end{array}$ \\
\hline Family participation in recreational or fun events (1) & 2.48 & 1.10 & NA & $\begin{array}{l}\text { We go to movies, sport events, or do other fun activities } \\
\text { together as a family ( } 4 \text {-pt Likert, } 1=\text { hardly ever, } \\
4=\text { often) }\end{array}$ \\
\hline
\end{tabular}

${ }^{a}$ Bivariate correlation.

\section{Cumulative promotive and risk factors indices}

Each student was given a score of 1 if the original score was equal to or above the cutoff point, or a zero if this score was below the cutoff point. Cumulative indices were computed by summing the promotive and risk factors, respectively, for each individual. The actual range for cumulative promotive factors was 0 to 17 (mean score $=5.26 ; S D=3.32$ ) and the range for cumulative risk factors was 0 to 15 (mean score $=4.38, S D=3.19$ ). The correlation between the promotive and risk factor indices was $-0.32(p<0.01)$.

Data analysis

Hierarchical multiple regression was used in both crosssectional and longitudinal analyses with polydrug use as the dependent variable. A four-step hierarchical multiple regression was conducted for the Year 1 cross-sectional analyses. The first step included three demographic variables entered as a block (gender, race and mother's education), the cumulative risk factor index was entered in the second step, the cumulative promotive factor index in the third (test of compensatory model of resiliency), and the fourth step included the cumulative risk by cumulative promotive interaction term (test of the protection model of resiliency). All measures were centered before they were entered in the equation (or multiplied to create the interaction term) to help reduce multicollinearity (Aiken \& West, 1991). The longitudinal regression analysis for the dependent variable measured at Year 4 was conducted. This longitudinal analysis included Year 1 polydrug use index entered in step one, in order to study change in the level of substance use involvement between Years 1 and 4 (Pedhazur, 1982).

We also repeated these two hierarchical regression analyses with the promotive factor index entered in equations before risk factor index in order to determine how much variance the promotive factor index explained without first accounting for risk factor variance.

\section{Results}

\section{Attrition}

A comparison of youth included in the cross-sectional analysis $(n=624)$ with youth omitted due to missing data indicated no differences for gender $\left(\chi^{2}=0.024\right.$; $\mathrm{ns})$, ethnicity $\left(\chi^{2}=3.07 ; \mathrm{ns}\right)$ and mother educational status $(t(1,785)=-0.714$; ns). In addition, no differences were found for the cumulative risk factor in$\operatorname{dex}(t(1,741)=-1.68 ; \mathrm{ns})$, the cumulative promotive factor index $(t(1,792)=1.77$; ns), or for polydrug use $(t(1,767)=0.148 ; \mathrm{ns})$.

A comparison of youth included in the longitudinal analysis $(n=531)$ with youth omitted due to missing data revealed ethnicity approached significance $\left(\chi^{2}=5.69\right.$, $p<0.58$ ). More African American students were in the group with missing data (84\%) than in the group included in the analysis (78\%). No differences were found for gender $\left(\chi^{2}=0.10 ; n s\right)$ or mother's education $(t(1,785)=0.320 ; n s)$. Youth with missing data had a higher cumulative risk level $(\overline{\mathrm{x}}=4.91, S D=3.32)$ than youth included in the analysis 
Table 2 Cross-sectional hierarchical multiple regression results predicting polydrug use from the cumulative risk and promotive factors (Year 1)

\begin{tabular}{|c|c|c|c|c|}
\hline Step & Predictor measures & Final $B$ & $R^{2}$ & $R^{2}$ change \\
\hline \multirow[t]{4}{*}{1} & Demographics & & 0.004 & - \\
\hline & Gender & -0.098 & & \\
\hline & Race & $0.372^{*}$ & & \\
\hline & Mother's education & 0.042 & & \\
\hline 2 & Risk factor index & $0.635^{* *}$ & 0.288 & $0.284^{* *}$ \\
\hline 3 & Promotive factor index & $-0.123^{* *}$ & 0.293 & $0.005^{*}$ \\
\hline 4 & Risk $\times$ promotive factor interaction & $-0.034^{* *}$ & 0.300 & $0.007^{* *}$ \\
\hline
\end{tabular}

$(\overline{\mathrm{x}}=4.17, S D=3.11)(t(1,741)=-2.86 ; p<0.004)$, and lower cumulative asset level $(\overline{\mathrm{x}}=4.91, S D=3.16)$ compared to $(\overline{\mathrm{x}}=5.43, S D=3.38)(t(1,792)=2.14, p<0.03)$. No differences were found for baseline polydrug use $(F(1,767)=-0.59, \mathrm{~ns})$.

Cross-sectional data: multiple regression analyses

After controlling for demographics, the multiple regression of polydrug use at Year 1 indicated main effects for cumulative risks index $(F$-change $(1,619)=246.66 ; p<0.001)$, cumulative promotive factors index $(F$-change $(1,618)=4.65$; $p<0.03)$, and for the risk by promotive factor interaction $(F$-change $(1,617)=6.13 ; p<0.01)$. The cross-sectional regression model explained almost $30 \%$ of the variance in adolescent polydrug use. Demographic variables entered as a block were not significant as a predictor in cross-sectional analysis $(F$-change $(1,620)=0.88$; ns). Table 2 reports unstandardized coefficients $B$ at the final step, the incremental $R^{2}$, and the $R^{2}$ change at each step of the regression analysis of polydrug use on cumulative risk and promotive factors indices.

Figure 1 presents the decomposition of the interaction effect. The graph depicts the relationship between the promo-

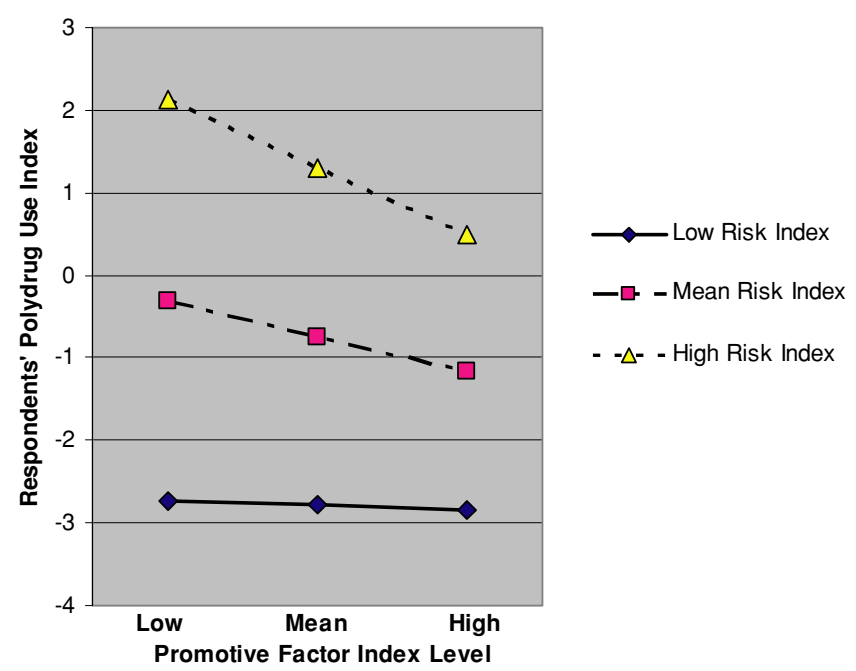

Fig. 1 Relationship between level of promotive factor index and respondents' polydrug use for low, mean and high risk index tive factors and polydrug use for the mean and one standard deviation above and below the mean of cumulative risk factor index. High risk is associated with more polydrug use, especially when the level of promotive factors is low, but high level of the promotive factors is associated with lower polydrug use. Low risk is associated with low level of polydrug involvement, regardless of level of promotive factors.

Longitudinal data: multiple regression analyses

After controlling for Year 1 polydrug use, the multiple regression of polydrug use at Year 4 indicated main effects for demographics $(F$-change $(1,526)=15.31 ; p<0.001)$, cumulative risks index $(F$-change $(1,525)=36.73 ; p<$ $0.001)$ and cumulative promotive factors index ( $F$-change $(1,524)=4.49 ; p<0.035)$. No effect was found for the risk by promotive factor interaction in the longitudinal analysis. The amount of variance explained in change in polydrug use reached $32 \%$. Table 3 reports unstandardized coefficients $B$ at the final step, the incremental $R^{2}$, and the $R^{2}$ change at each step of the longitudinal regression analysis of polydrug use on cumulative risk and promotive factor indices.

\section{Additional analyses}

With promotive factor index entered first, the hierarchical multiple regression of polydrug use revealed stronger main effect for cumulative promotive factor index than in previous analyses: cross-sectional $(F$-change $(1,619)=40.78 ; p<$ $0.001 ; R^{2}$-change $\left.=0.062\right)$, and longitudinal after controlling Year 1 polydrug use $(F$-change $(1,525)=12.14 ; p<0.001$; $R^{2}$-change $\left.=0.017\right)$. The main effects for cumulative risk factor index remained highly significant regardless of the order of entry.

\section{Discussion}

Our results indicate a main effect for the promotive factor index supporting the compensatory model of resiliency both cross-sectionally and longitudinally. Cumulative risk factors accounted for most of the explained variance of polydrug 
Table 3 Longitudinal hierarchical multiple regression results predicting polydrug use change between Years 1 and 4 from the cumulative risk and promotive factors

\begin{tabular}{lllll}
\hline Step & Predictor measures & Final $B$ & $R^{2}$ & $R^{2}$ change \\
\hline 1 & Year 1 Polydrug use & $0.299^{* *}$ & 0.206 & $0.206^{* *}$ \\
2 & Demographics & & 0.269 & $0.064^{* *}$ \\
& Gender & $0.667^{*}$ & & \\
& Race & $1.143^{* *}$ & & \\
& Mother's education & $-0.218^{*}$ & & $0.048^{* *}$ \\
3 & Risk factor index & $0.312^{* *}$ & 0.317 & $0.006^{*}$ \\
4 & Promotive factor index & $-0.101^{*}$ & 0.323 & 0.000 \\
5 & Risk $\times$ promotive factor interaction & 0.000 & 0.323 & \\
\hline
\end{tabular}

${ }^{*} p<0.05$.

${ }^{* *} p<0.01$.

0.32

0.006

use measured at Year 1 (9th grade) and polydrug use change within high school years (between 9th and 12th grade). Notably, the cumulative promotive factors added additional explanatory power in all of our regression models. The main effects of promotive factors, though small in magnitude, are consistent with most previous research on adolescent externalizing problems that utilized a cumulative risk and protective factor approach (Beam, Gil-Rivas, Greenberg, \& Chen, 2002; DeWit et al., 1995; Jessor et al., 1995; Newcomb \& Felix-Ortiz, 1992; Pollard et al., 1999; Sullivan \& Farrell, 1999). These researchers have also found relatively small compensatory effects. Our analyses build on this past work by examining the compensatory model of resiliency in a longitudinal study embracing four high school years. It is also notable that we found these results with a sample of predominantly African American, urban youth.

Although researchers have found evidence supporting a compensatory model of resiliency for adolescent substance use and other problem behaviors, the risk factors tend to be much stronger predictors than the promotive factors. As Bowen and Flora (2002) pointed out summarizing the results of these several studies, "cumulative measures of risks explained up to $22 \%$ of the variance in externalizing behavior, compared with a maximum of $1.3 \%$ for cumulative measures of protection" (p. 528). In general, results from our study and others (Beam et al., 2002; Jessor et al., 1995; Newcomb \& Felix-Ortiz, 1992; Pollard et al., 1999; Sullivan \& Farrell, 1999; Zimmerman, Bingenheimer, \& Notaro, 2002) suggest that promotive factors, compared to risk factors have less predictive effect on substance use, and explain less percentage of the variance in adolescent problem behaviors. The modest magnitude of these effects, however, does not mean they are unimportant. Small effects may be impressive when the dependent variable is difficult to influence (Prentice \& Miller, 1992) as is the case for adolescent substance use.

It is also worth noting that effect size for the compensatory model increases when promotive factors are entered before the risk factors in our regression model. Newcomb and FelixOrtiz (1992) entered their cumulative protective factor index before their cumulative risk factor index in their regression models. Most researchers, however, who use a multiple fac- tor approach enter the risk factor index first in the regression equations (Beam et al., 2002; Dekovic, 1999; Jessor et al., 1995). This latter order of entry represents the more consistent approach to test resilience theory. Yet, while testing a compensatory model of resilience, the order of entry might be considered as optional because this model assumes that risk and promotive factors contribute independently to the outcome. If entered first into regression models, promotive factors explained $6.2 \%$ of variance in adolescent polydrug use in cross-sectional analysis, as compared to $0.5 \%$ when they are entered after the risk factor index. It is also notable that the compensatory effect was somewhat more salient when the promotive factor index was entered before risk factors in the longitudinal model as well. In our longitudinal analysis, if entered first, promotive factors explained $1.7 \%$ of variance in adolescent polydrug use, as compared to $0.6 \%$ when they are entered after.

Our cross-sectional analysis results also suggest that promotive factors modify the effects of the risk factors in adolescent substance use. This provides support for the protective model of resiliency. This finding is consistent with other cross-sectional research (DeWit et al., 1995; Jessor et al., 1995; Pollard et al., 1999; Sullivan \& Farrell, 1999). The differences in the downward slope of three regression lines show that the moderating (protective) effect of cumulative promotive factors was strongest for youth who were exposed to the highest risk level, and weakest for youth who were exposed to the low level of risk. This indicates that the protective effects of cumulative promotive factors for adolescent polydrug use are stronger when risk is high than when risk is moderate or low. This suggests that the resilience process may be most effective when risk exposure is relatively high. This finding is consistent with conceptualizations of resilience (Luthar \& Zigler, 1991; Rutter, 1987) as well as with empirical work (Bowen \& Flora, 2002; Epstein et al., 2001; Jessor et al., 1995).

The protective factor model evidenced by cross-sectional analysis was not supported in our longitudinal analysis. Factors associated with a longitudinal design might account for a lack of support for a protective model. Attrition, which is often a problem in longitudinal studies, might influence the results by leading to unequal elimination of high-risk youth, 
a group who accounted for the biggest protective effect in the cross-sectional analysis. Notably, other researchers also failed to find a longitudinal effect for the protective model (Jessor et al., 1995; Sullivan \& Farrell, 1999). The fact that we found support for the compensatory (direct) model but not the protective model suggests that protective mechanisms may have changed during high school. Further work is clearly needed to explain how protective processes may operate during high school, and especially how they interact with risk factors over time.

It is possible that we did not assess vital, developmentally relevant promotive factors in the early years of the study. Adolescence is a time of significant change in youths' lives and perhaps promotive factors measured when youths are 13-14 years old such as cognitive abilities, self-control, and future orientation (i.e., motivation to achieve for some future life purpose) might have played a critical role in moderating risk factor effects later in adolescence. In other words, because development of some promotive factors may be delayed compared to development of risk factors, a more developmentally sensitive method than our approach for measurement may be necessary. Different approaches can be used to strengthen the present study design and methods of analysis. Extensive longitudinal data collection with a gradual inclusion of developmentally appropriate promotive factors may be useful to track individual trajectories of personal development. Modeling techniques such as latent growth modeling and person-centered methodology may be helpful to illustrate different trajectories of promotive factors and their evolving interactions with risk factors across adolescence. Yet, it is also useful to measure the same factors over time to follow how they change developmentally, and how their change is associated with risk and resilience.

\section{Implications for prevention}

Our findings supporting compensatory and protective models of resiliency suggest that efforts to enhance promotive factors may be a useful approach for prevention strategies for adolescents exposed to risk. More accurate scientific knowledge on risks has led to development of the risk focused approach to drug abuse prevention in the 1980s and early 1990s (Hawkins et al., 1992). Although this approach has contributed to the development of more effective prevention programs, it was usually limited to interventions designed to reduce risks. This problem focused preventive strategy stresses vulnerability and deficits. Practitioners working with at-risk groups of children and adolescents, however, often cannot reduce their vulnerability or reverse their deficits. Thus, prevention programming focusing on assets and resources creates promising opportunities for practitioners and community organizations working with populations exposed to persistent problems such as children from low income families, chil- dren of alcoholics, or children and adolescents with serious emotional problems.

Recently, a number of programs were developed to strengthen individual skills and develop external resources (Catalano et al., 2002; Greenberg, Domitrovich, \& Bumbarger, 2001). The Fathers and Sons Program is another example of an intervention for children at risk, and focuses on enhancing family assets and resources found to contribute to healthy youth development (Caldwell et al., 2004b). This program is designed to prevent or reduce substance use, violent behavior, and early sexual initiation among African American, male pre-adolescents whose fathers do not live in the same households. Father-absent households are considered a risk factor because they are often associated with very little or no father involvement in the lives of their children. The Fathers and Sons Program aims to strengthen and sustain father involvement, improve effective father-son communication and enhance parenting skills. The focus on fathers as a source of resilience for their sons is based on earlier findings that non-resident, African American fathers who remain appropriately involved (provide support, share activities and express concern for school achievement) can have positive effects on their children's development (Zimmerman et al., 2000). In addition, the program addresses positive racial identity and socialization, which were found to be associated with less substance use among African American youth (Caldwell, Kohn-Wood, Schmeelk-Cone, Chavous, \& Zimmerman, 2004a).

In sum, our findings contribute to growing body of research that supports a more strength-building approach to prevention (Bowen \& Flora, 2002; Luthar \& Cicchetti, 2000; Zimmerman et al., 2000) and also fits with current notions of positive youth development (Catalano et al., 2002). Further, our results suggest that in order to maximize prevention effects it may be most useful to include individual, peer, family, and community promotive factors. By emphasizing multiple assets and resources, this approach may overcome the limitations of more traditional prevention strategies that typically focus on only one level.

\section{Study limitations}

Some limitations of our study should be noted. First, the sample included youths who had 8th-grade GPAs of 3.0 or lower. Exclusion of the highest academic achieving students may limit generalizability of our study. The results of the current study should be considered in the social and cultural context within which this research was conducted (urban, Midwestern, largely African American), and consequently may not generalize to all urban youth. It is also possible that this sampling strategy may threaten internal validity of survey data by limiting the variability in promotive factor scores. This may be why our cumulative promotive factors index 
explained small amounts of variance in the cross-sectional analysis and did not moderate the effects of the risk factor index (i.e., interaction effect) in our longitudinal analysis. Yet, even though our sample limitations may have reduced variance to explain, we found effects for the promotive factor index. This suggests that with more variance to explain, we may have found stronger effects for the promotive factor. Thus, our study may have been a conservative test of resiliency theory using a cumulative risk and promotive factor approach suggesting future research with more representative samples is warranted.

In addition, although our sampling strategy poses a limitation of the study, several factors may mitigate this problem. This study provides useful insights about a sub-population of largely African American, low academic achieving, urban youth identified as being at risk for several negative outcomes. From this perspective, our sample may be considered a vital group to study, because our results may generalize to youth at greater than average risk for negative outcomes. This may be especially useful because these are the youth for whom urban interventions are often developed. It is also notable that by 12th grade the range of GPA included many A students (Zimmerman, Caldwell, \& Bernat, 2002). This suggests that a number of primarily low achieving students improved their GPAs during high school, resulting in more heterogeneity in academic achievements. Furthermore, although this research focused on an at-risk group of youth, most of the study variables (including measures of promotive factors) were not widely skewed and were adequately distributed.

A second limitation of the study is that we faced an unequal attrition while examining longitudinal data. As can be expected, youth omitted due to missing data had on average a higher risk factor index score and lower promotive factor index score. This selection of students in longitudinal analyses may have biased our sample towards lower risk students. This may explain why our longitudinal analysis failed to reveal a protective effect.

Low internal reliability of some scales used to create multi-scale indices is another limitation of our study. Although most scales had acceptable internal reliability (Cronbach's alpha ranged from 0.62 to 0.82 ), four scales showed lower reliability ( $\alpha 0.55$ to 0.52 ). These four scales, however, only included 3 to 4 items which may limit alphas. The precision of the reliability estimate is directly related to the number of the scale items (Nunnally, 1978). If, for example, we double the number of items in these scales and then estimate reliability based on the formula described by Nunnally, all four scales would reach acceptable Cronbach's alpha coefficients (Nunnally, 1978). Furthermore, because all scales were part of a multi-scale factor and were not analyzed separately, their individual reliabilities may be less important. In fact, it could be argued that the cumulative factor indices increase overall reliability of measurement of risk and protective factors.

It is also noteworthy that we included only limited measures of community-level risk and promotive factors. In our study, individual, peer and family-level factors were better represented. Our community-level measures were somewhat more limited as they did not include potentially important measures for AOD outcomes such as availability of drugs and neighborhood characteristics (e.g., concentrated disadvantage). Some researchers have argued that these factors may play an important role in adolescent substance use behavior (Hawkins et al., 1992; Hays, Hays, \& Mulhall, 2003). It may be useful to include more contextual factors in future research. Finally, our approach of using the upper (or lower) quartile as the cutoff point for defining a variable as a risk or promotive factor may have underestimated the level of risk or promotion for a particular variable. Although the quartile strategy provides an approach for defining relative risk (or promotion), it may not be as effective for defining absolute risk (or promotion). This may be most evident for our measure of early substance use because youth who used at age 12 (the mean for this variable), were not given a risk value in the cumulative risk index even though substance use at 12 years of age may also be a risk factor for subsequent use. Thus, our cumulative risk measure may actually be a more conservative estimate of risk than the actual risk in our sample. Nevertheless, we were most interested in relative risk within our sample, and our lower cutoff age for defining risk would, again, have the effect of limiting our ability to detect effects because we may have excluded some youth at risk from receiving a risk score for the cumulative index. Conversely, we may have also excluded some youth from receiving a positive score for the cumulative promotive index, which may explain why we did not find longitudinal protective effects for this index.

\section{Conclusion}

Despite these limitations, this study covering four high school years contributes to the growing body of research suggesting that promotive factors play a vital role in adolescent development. The cross-sectional and longitudinal compensatory effects, as well as the cross-sectional protective effect on adolescent polydrug use support past research in different populations and add to research on resiliency theory by using a cumulative risk and promotive factor approach. Our results support the idea that even though cumulative risk is a heavy burden, promotive factors can, nevertheless, help youth overcome their deleterious effects. The results also suggest that prevention efforts incorporating salient promotive factors that operate across multiple levels may be a beneficial approach. This study provides useful connections to empowerment theory because of the many overlapping 
constructs (Zimmerman, 2005). Zimmerman (1995) points out that psychological empowerment is a developmental construct that varies by population and context. Adolescent resilience may be one example of psychological empowerment in a developmental context because it involves youths' sense of control and confidence, actions to avoid deleterious factors that increase risk for negative outcomes, and connections to adults (both in and out of the family) to help them overcome risk and achieve their goals. Luthar and Cicchetti (2000) also briefly suggest that empowerment theory may be related to adolescent resiliency. Our study supports this notion by finding that these same factors help moderate the negative consequences of the risks adolescents face. Thus, resilient youth may, in effect, be empowered to overcome risk and adversity in their lives. Notably, our study also suggests that adolescent resiliency develops from both psychological as well as social and ecological factors.

Acknowledgmnets Support for this research was provided by a postdoctoral fellowship from Fogarty International Substance Abuse Research Program Grant No. 1-D43-TW05818 to Krzysztof Ostaszewski and National Institute on Drug Abuse Grant No. DA07484 to Marc A. Zimmerman.

We want to thank the Flint Community Schools and especially the students who agreed to participate in this study. We also thank the anonymous reviewers who helped us improve the manuscript.

\section{References}

Aiken, L. S., \& West, S. G. (1991). Multiple regression: Testing and interpreting interactions. Newbury Park, CA: Sage Publications.

Arthur, M., Hawkins, D., Pollard, J., Catalano, R., \& Baglioni, A. (2002). Measuring risk and protective factors for substance use, delinquency, and other adolescent problem behaviors. The communities that care youth survey. Evaluation Review, 26(6), 575601.

Baer, J., MacLean, M., \& Marlatt, G. (1998). Linking etiology and treatment for adolescent substance abuse: Toward a better match. In R. Jessor (Ed.), New perspectives on adolescent risk behavior (pp 182-220). Cambridge University Press.

Beam, M. R., Gil-Rivas, V., Greenberg, E., \& Chen, C. (2002). Adolescent problem behavior and depressed mood: Risk and protection within and across social context. Journal of Youth and Adolescence, 31(5), 343-357.

Blitstein, J. L., Murray, D. M., Lytle, L. A., Birnbaum, A. S., \& Perry, C. L. (2005). Predictors of violent behavior in an early adolescent cohort: Similarities and differences across genders. Health Education \& Behavior, 32(2), 175-194.

Bowen, N. K., \& Flora, D. B. (2002). When is it appropriate to focus on protection in interventions for adolescents? American Journal of Orthopsychiatry, 72(4), 526-538.

Bronfenbrenner, U. (1986). Ecology of the family as a context for human development: Research Perspectives. Developmental Psychology, 22(6), 723-742.

Bryant, A. L., \& Zimmerman, M. A. (2002). Examining the effects of academic beliefs and behaviors on changes in substance use among urban adolescents. Journal of Educational Psychology, 94 , 621-637.
Caldwell, C. H., Kohn-Wood, L. P., Schmeelk-Cone, K. H., Chavous, T. M., \& Zimmerman, M. A. (2004a). Racial discrimination and racial identity as risk or protective factors for violent behaviors in African American young adults. American Journal of Community Psychology, 33, 91-105.

Caldwell, C. H., Wright, J. C., Zimmerman, M. A., Walsemann, K. M., Williams, D., \& Isichei, P. A. C. (2004b). Enhancing adolescent health behaviors through strengthening non-resident father-son relationships: A model for intervention with African American families. Health Education Research, 19, 644-656.

Catalano, R., Berglund, L., Ryan, J., Lonczak, H., \& Hawkins, D. (2002). Positive youth development in the United States: Research findings on evaluations of positive youth development programs. Prevention \& Treatment, Vol. 5, Article 15, http://journals.apa.org /prevention/volume5.

Clark, D. B., \& Winters, K. C. (2002). Measuring risks and outcomes in substance use disorder prevention research. Journal of Consulting and Clinical Psychology, 70(6), 1207-1223.

Dekovic, M. (1999) Risk and protective factors in the development of problem behavior during adolescence. Journal of Youth and Adolescence, 28(6), 667-685.

DeWit, D. J., Silverman, G., Goodstadt, M., \& Stoduto, G. (1995). The construction of risk and protective factor indices for adolescent alcohol and other drug use. Journal of Drug Issues, 25(4), 837663.

Dielman, T. E., Butchart, A. T., \& Shope, J. T. (1991). Structural equation model tests of patterns of family interaction, peer alcohol use, and intrapersonal predictors of adolescent alcohol use and misuse. Journal of Drug Education, 23, 273-316.

Duncan, S. C., Duncan, T. E., Biglan, A., \& Ary, D. (1998). Contributions of the social context to development of adolescent substance use: a multivariate latent growth modeling approach. Drug and Alcohol Dependence, 50, 57-71.

Epstein, J. A., Botvin, G. J., Griffin, K.W., \& Diaz, T. (2001). Protective factors buffer effects of risk factors on alcohol use among innercity youth. Journal of Child \& Adolescent Substance Abuse, 11, 77-90.

Fergus, S., \& Zimmerman, M. A. (2005) Adolescent resilience: A framework for understanding healthy development in the face of risk. Annual Review of Public Health, 26, 399-419.

Fraser, M. W., Richman, J. M., \& Galinsky, M. J. (1999). Risk, protection, and resilience: Toward a conceptual framework for social work practice. Social Work Research, 23(3), 131-143.

Garmezy, N. (1985). Stress-resistant children: The search for protective factors. In J. Stevenson (Ed.), Recent research in developmental psychopathology (pp. 213-234). New York: Pergamon Press.

Garmezy, N., Masten, A. S., \& Tellegen, A. (1984). The study of stress and competence in children: A building block for developmental psychopathology. Child Development, 55, 97-111.

Greenberg, M., Domitrovich, C., \& Bumbarger, B. (2001). The prevention of mental disorders in school-aged children: Current state of the field. Prevention \& Treatment, Vol. 4, Article 1, http://journals.apa.org / prevention/volume4.

Griffin, K., Botvin, G., Scheier, L., Doyle, M., \& Williams, C. (2003). Common predictors of cigarette smoking, alcohol use, aggression, and delinquency among inner-city minority youth. Addictive Behaviors, 28, 1141-1148.

Hawkins, J. D., Catalano, R. F., Miller J. Y. (1992). Risk and protective factors for alcohol and other drug problems in adolescence and early adulthood: Implication for substance abuse prevention. Psychological Bulletin, 112(1), 64-105.

Hays, S. P., Hays, C. E., \& Mulhall, P. F. (2003). Community risk and protective factors and adolescent substance use. The Journal of Primary Prevention, 24(2), 125-142. 
James, S. A., Strogatz, D. S., Wing, S. B., \& Ramsey, D. L. (1987). Socioeconomic status, John Henryism, and hypertension in Blacks and Whites. American Journal of Epidemiology, 126, 664-673.

Jessor, R., Van Den Bos, J., Vanderryn, J., Costa, F., \& Turbin, M.(1995). Protective factors in adolescent problem behavior: moderator effects and developmental change. Developmental Psychology, 31(6), 923-933.

Johnston, L. D., O’Malley, P. M., \& Bachman, J. G. (2003). Monitoring the Future national survey results on drug use, 1975-2002. Secondary school students Vol. I (NIH Publication No. 03-5375). Bethesda, MD: National Institute on Drug Abuse.

Kandel, D., Yamaguchi, K., \& Chen, K. (1992). Stages of progression in drug involvement from adolescence to adulthood: Further evidence for the gateway theory. Journal of Studies on Alcohol, 53, 447-457.

Kegler, M. C., Oman, R. F., Vesley, S. K., McLeroy, K. R., Aspy, C. B., Rodine, S., \& Marshall, L. (2005). Relationship among youth assets and neighborhood and community reseources. Health Education \& Behavior, 32(3).

Kumpfer, K. (1999). Factors and processes contributing to resilience. The resilience framework. In M. Glanz \& J. Johnson (Eds.), Resilience and development. Positive life adaptations (pp. 179-224). New York: Kluwer Academic/Plenum Publisher.

Kumpfer, K., Olds, D., Alexander, J., Zucker, R., \& Gary, L. (1998) Family etiology of youth problems. In R. Ashery, E. Robertson, \& K. Kumpfer (Eds.), Drug Abuse Prevention Through Family Interventions (pp. 42-77). NIDA Research Monograph 177, U.S. Department of Health and Human Services.

Kumpfer, K., \& Turner, C. (1990/1991). The social ecology model of adolescent substance abuse: Implications for prevention. International Journal of the Addictions, 25(4A), 435-463.

Luthar, S. S., \& Cicchetti, D. (2000). The construct of resilience: Implications for interventions and social policies. Developmental Psychopathology, 12, 857-885.

Luthar, S. S., Cicchetti, D., \& Becker, B. (2000). The construct of resilience: A critical evaluation and guidelines for future work. Child Development, 71(3), 543-562.

Luthar, S., \& Zigler, E. (1991). Vulnerability and competence: A review of research on resilience in childhood. American Journal of Orthopsychiatry, 61(1), 6-22.

Moos, R. H., \& Moos, D. S. (1981). Family Environment Scale Manual. Palo Alto, CA: Consulting Psychologists.

National Research Council and Institute of Medicine (2002). In: Community Programs to Promote Youth Development (Eds.), J. Eccles \& J. A. Gootman. Washington, DC: National Academy Press.

Newcomb, D. N., \& Felix-Ortiz, M. (1992). Multiple protective and risk factors for drug use and abuse: Cross-sectional and prospective findings. Journal of Personality and Social Psychology, 63(2), 280-296.

Newcomb, M. D., Maddahian, E., \& Bentler, P. M. (1986). Risk factors for drug use among adolescents: Concurrent and longitudinal analyses. American Journal of Public Health, 76, 525-531.

Nunnally, J. (1978). Psychometric theory (2nd edition). New York: McGraw-Hill.

O’Malley, P. M., Johnston, L. D., \& Bachman, J. G. (1998). Alcohol use among adolescents. Alcohol Health and Research World, 22(2), $85-93$.

Pedhazur, E. J. (1982). Multiple regression in behavioral research: Explanation and prediction (2nd edition). Fort Worth, TX: Holt, Rinehart and Winston, Inc.

Petraitis, J., Flay, B., \& Miller, T. (1995). Reviewing theories of adolescent substance use: Organizing pieces in the puzzle. Psychological Bulletin, 117(1), 67-86.

Pollard, J. A., Hawkins, J. D., \& Arthur, M. W. (1999). Risk and protection. Are both necessary to understand diverse behavioral outcomes in adolescence? Social Work Research, 23(3), 145-158.
Prentice, D. A., \& Miller, D. (1992). When small effects are impressive. Psychological Bulletin, 112(1), 160-164.

Procidano, M. E., \& Heller, K. (1983). Measures of perceived social support from friends and from family: Three validation studies. American Journal of Community Psychology, 11, 1-24.

Resnick, M. D., Bearman, P. S., Blum, R. W., Bauman, K. E., Harris, K. M., Jones, J., Tabor, J., Beuhring, T., Sieving, R. E., Shew, M., Ireland, M., Bearinger, L.H., \& Udry, J. R. (1997). Protecting adolescents from harm. Findings from the National Longitudinal Study on Adolescent Health. Journal of the American Medical Association, 278(10), 823-832.

Rutter, M. (1987). Psychological resilience and protective mechanisms. American Journal of Orthopsychiatry, 57(3), 316-331.

Salem, D., Zimmerman, M. A., \& Notaro, P. (1998). Effects of family structure, family process, and father involvement on psychological outcomes among African American adolescents. Family Relations, 47, 331-341.

Sandler, I., Wolchik, S., Davis, C., Haine, R., \& Ayers, T. (2003). Correlational and experimental study of resilience in children of divorce and parentally bereaved children. See Ref. 63a, pp. 213243.

Scheier, L., Botvin, G., \& Baker, E. (1997). Risk and protective factors as predictors of adolescent alcohol involvement and transitions in alcohol use: A prospective analysis. Journal of Studies on Alcohol, $58,652-667$.

Simons-Morton, B. G., Hartos, J. L., \& Haynie, D. L. (2004). Prospective analysis of peer and parental influences on minor aggression among early adolescents. Health Education \& Behavior, 31(1), 22-33.

Stacy, A. U., Newcomb, M. D., \& Bentler, P. M. (1992). Interactive and higher-order effects of social influences on drug use. Journal of Health and Social Behavior, 33, 226-241.

Stein, J. A., Newcomb, M. D., \& Bentler, P. M. (1986). Stability and change in personality: A longitudinal study from early adolescence to young adulthood. Journal of Research in Personality, 20, 276291.

Sullivan, T. N., \& Farrell, A. D. (1999). Identification and impact of risk and protective factors for drug use among urban African American adolescents. Journal of Clinical Child Psychology, 28(2), 122136.

Wills, T. A., \& Cleary, S. D. (1996). How are social support effects mediated? A test with parental support and adolescent substance use. Journal of Personality and Social Psychology, 71(5), 937952.

Wills, T., Vaccaro, D., \& McNamara, G. (1992). The role of life events, family support, and competence in adolescent substance use: a test of vulnerability and protective factors. American Journal of Community Psychology, 20(3), 349-374.

Wills, T. A., Yaeger, A. M., \& Sandy, J. M. (2003). Buffering effect of religiosity for adolescent substance use. Psychology of Addictive Behaviors, 17(1), 24-31.

Windle, M. (1994). Substance use, risky behaviors, and victimization among a US national adolescent sample. Addiction, 89, 175-182.

Windle, M., Miller-Tutzauer, C., \& Domenico, D. (1992). Alcohol use, suicidal behavior, and risky activities among adolescents. Journal of Research on Adolescence, 2(4), 317-330.

Zimmerman, M. A. (1995). Psychological empowerment: Issues and illustrations. American Journal of Community Psychology, 23, 581-599.

Zimmerman, M. A. (2000). Empowerment theory: Psychological, organizational and community levels of analysis. In J. Rappaport \& E. Seidman (Eds.), Handbook of Community Psychology, Chapter 2 (pp. 43-63). New York: Plenum Press.

Zimmerman, M. A. (March 2005). Youth violence: Application of empowerment theory \& adolescent resilience paper presented at Columbia University, New York, NY. 
Zimmerman, M. A., \& Arunkumar, R. (1994). Resiliency research: Implications for schools and policy. Social Policy Report: Society for Research in Child Development, 8(4), 1-18.

Zimmerman, M. A., Bingenheimer, J., \& Notaro, P. (2002). Natural mentors and adolescent Resiliency: A study with urban youth. American Journal of Community Psychology, 30(2), 221-243.

Zimmerman, M. A., Caldwell, C. H., \& Bernat, D. H. (2002). Discrepancy between self-report and school record GPA: Correlates with psychosocial outcomes among African American adolescents. Journal of Applied Social Psychology, 32(1), 86-109.
Zimmerman, M. A., Salem, D. A., \& Notaro, P. C. (2000). Make room for daddy II: The positive effects of fathers' role in adolescent development. In R. D. Taylor \& M. C. Wang (Eds.), Resilience across contexts: Family, work, culture, and community (pp. 233253). Mahwah, NJ: Lawrence Erlbaum Associates, Inc.

Zimmerman, M. A., Steinman, K. J., \& Rowe, K. J. (1998). Violence among urban African American adolescents: The protective effects of parental support. In X. B. Arriaga \& S. Oskamp (Eds.), Addressing Community Problems: Psychological Research and Interventions (pp. 78-103). Thousand Oaks, CA: Sage. 